Emerging markets perspectives on G-20 led financial reforms

Ashima Goyal and Akhilesh Verma

Indira Gandhi Institute of Development Research, Mumbai March 2019 


\title{
Emerging markets perspectives on G-20 led financial reforms
}

\author{
Ashima Goyal and Akhilesh Verma
}

Email(corresponding author): ashima@igidr.ac.in

\begin{abstract}
The chapter examines progress as well as continuing concerns in G-20 led financial reforms, with particular emphasis on emerging markets (EMs). Although risks remain they are of a lower order of magnitude compared to those in the pre global crisis period. But progress is slowest in areas of concern to EMs. Question marks over liquidity in markets as quantitative easing is withdrawn are echoed in EMs, which also face risk-off outflows and volatile exchange rates in this period. Leverage is high in some EMs after a period of low global interest rates and risk-on inflows in search of yields. But EMs are largely left to handle volatility themselves. Even the advice given to them or its understanding in policy circles or markets is not sufficiently nuanced. There are arguments for and against financial tightening as the best response to achieve financial stability. These are examined in the context of experiences in some specific EMs. Implications are drawn for G-20 policies and for its advice to EMs.
\end{abstract}

Keywords: G-20; Financial reforms; Emerging markets

JEL Code: F42, F53, G15

\section{Acknowledgements:}

Some of these ideas were presented at the 10th Annual International G20 Conference at ICRIER and are forthcoming in a conference volume to be published by Springer. We thank the participants for useful feedback and Reshma Aguiar for secretarial assistance. 


\section{Emerging markets perspectives on G-20 led financial reforms}

\section{Introduction}

G-20 countries aim to maintain the open and integrated structure of the international financial system while initiating a comprehensive program of global financial reforms ${ }^{1}$ to:

(1) Strengthen the financial system and make it more resilient through lower leverage, higher buffers, better risk management and governance and a sound compensation structure.

(2) End too big to fail (TBTF) institutions through requirements for higher loss absorbency for global systemically important financial institutions (G-SIFIs), subjecting such institutions to intensive supervision and establishing a legal and regulatory framework to allow resolution without government support.

(3) Make derivative markets safer through the requirement to report all over-thecounter (OTC) derivatives to trade repositories, clearance of all standardized contracts through central counter-parties with trading on electronic platforms or exchanges and subjecting non-centrally cleared contract to minimum margin and higher capital requirements,

(4) Transform shadow banking into market-based finance through oversight and strong regulation.

(5) Develop a macroprudential policy framework, improve accounting, auditing and disclosure, promote adherence to international standards and increase international policy coordination.

Financial stability board (FSB) set up in 2009 was tasked with coordinating reforms, with 24 countries including G-20 countries under FSB jurisdiction and monitored for timely and consistent implementation to reduce regulatory arbitrage across countries ${ }^{2}$.

Global banks capital and liquidity buffers have improved. The financial system has become more diversified through enhancement of market-based finance. Growth in total and bank credit has improved in most countries and the cost of financing remains low mainly due to advanced economies' (AEs) accommodative monetary policy. While there is steady progress in objectives (1) to (3), progress is slow for (4) and (5).

\footnotetext{
${ }^{1}$ FSB $(2015,2016$ \& 2017) annual reports

2 These countries are Argentina, Australia, Brazil, Canada, China, France, Germany, Hong Kong, India, Indonesia, Italy, Japan, Mexico, Netherlands, Republic of Korea, Russia, Saudi Arabia, Singapore, South Africa, Spain, Switzerland, Turkey, United Kingdom and the United States.
} 
Over the past few years, FSB has completed an assessment of two core reforms: OTC derivatives and shadow banking. Central clearing has simplified the earlier complex process of derivative exposure and central counterparties have strengthened. Higher collateral in the financial system, improved transparency through trade repositories, better data quality are some outcomes of reforms in OTC derivatives, while those in the shadow banking system have reduced vulnerabilities in money market funds and repo markets.

There are still areas of weakness, however, such as concerns about market liquidity, leverage and spillovers on emerging markets (EMs). These create difficulties in maintaining an open and integrated global financial system.

International bank lending through European banks has declined since the global financial crisis (GFC). The move towards regionally funded lending increases the risk of geographic market segmentation. Financing through international debt markets has substantially increased, which further requires the development of global infrastructure for trading, clearing, settlement and measures to reduce volatility. On the EM side, there are challenges in implementing FSB reforms and concerns expressed over the excessive focus on banks, leading to slowdown in domestic bank credit, reduction of global bank exposure in their domestic markets and rising volatility of non-bank capital flows. Overall credit growth has been robust, however, in most countries.

The remainder of the paper is structured as follows: Section 2 discusses reform successes; section 3 brings out the key challenges remaining and assesses global risks; in this context section 4 further develops the risks and challenges from an EM perspective before section 5 concludes the paper with some suggestions for G-20.

\section{Reform successes}

\subsection{Stronger and more robust banks}

Much of the reforms have focused on banks, which are now stronger and more resilient with higher capital buffers. Leverage is lower although it can still go as high as 20-33 times lossabsorbing equity. 
Funding profiles have improved for banks due to less dependence on short-term wholesale funding and larger holding of more liquid assets such as government bond and deposits at the central banks, indicating that the core of banking has become more resilient than it was before GFC. Credit default swaps (CDS) premium and other indicators suggest that bank risk has declined. The credit rating of several international banks shows reduced expectations of too-big-to-fail stress.

The share of domestic systemically important banks (SIBs) in the global banking system has marginally decreased, but it remains large in absolute levels. Balance sheet size of SIBs in the US and Europe has remained stable in last few years (although post crisis it did rise with mergers), but it has increased in Asia (mostly in China).

All countries within FSB jurisdiction have put in place risk-based capital and liquidity rules from the Basel III regulatory framework. Rules on leverage ratio and net stable funding ratio (NFSR) came into force in most of the G-20 countries in January 2018. 20 countries published final rules for leverage ratio and 15 countries have published the final draft on NFSR.

Higher loss absorbency requirements for G-SIFIs are in place in all G-SIFIs headquarters; 23 jurisdictions have loss absorbency requirements for SIBs. Crisis management groups (CMG) have been formed in all SIBs and there are significant advances in resolution planning, however, cross-border resolution remains incomplete. The absence of insurance resolution regime with broader tools in G-SIFI home countries still impedes resolvability.

\subsection{Safer derivative markets}

Implementation of OTC derivative market reform is underway. Reforms related to trade reporting and interim capital requirement for non-centrally cleared derivatives are in advanced stages. Progress in final capital requirement, however, is relatively slow. Comprehensive central clearing framework is implemented in three-fourth while comprehensive margin requirement and trading framework are implemented in half of the countries under FSB jurisdiction.

Till end-2017 comprehensive trade reporting requirements were in place in all but one jurisdiction; 12 countries had adopted a framework for mandatory platform trading of 
standard OTC derivative covering $90 \%$ of the market. EU rules have increased margin and decreased leverage. Migration to electronic platforms has reduced counterparty risk

Aspects such as availability of client clearing service are constantly monitored. Additional work is underway to increase central counterparties (CCP) resilience, resolvability and recovery planning. Although home authorities have started to establish CMGs for systemically important CCPs, cross-border resolution mechanism is not in place. A joint group of regulators investigated interconnectedness of CCPs and SIBs, possible systemic risk and macroprudential $(\mathrm{MaP})$ regulations required.

\subsection{Transformation of shadow banking into market-based finance}

FSB, in collaboration with standard-setting bodies, has created a system-wide monitoring framework to analyze risk and global trends and strengthen oversight in the shadow banking system. Several issues are identified for further work such as data gaps in assessing financial stability risk, information sharing between authorities and bringing non-bank entities that could pose stability risk under regulation. Three countries, including the US, that account for a substantial part of the global market, have completed implementation of shadow banking reforms.

Liquid money market funds (MMFs) invest in risky corporate paper but offer fixed returns, which they were unable to sustain during the GFC, so that they 'broke the buck'; 21 FSB jurisdiction countries have now implemented the fair value approach for the evaluation of MMFs portfolios.

Improvements in auditing, disclosure, the spread of legal entity identifiers (LEI) and more uniform standards all aim to push shadow banking towards market-based finance. Haircuts are proposed for bonds and equities as well so as to extend countercyclical regulation beyond banks and cover markets more uniformly and broadly. Basel III wants banks to hold capital against client positions as well. Progress on liquidity management in the shadow banking system is not significant as yet, however.

\subsection{Adherence to international financial standards and other reforms}

FSB jurisdiction countries undergo a financial sector assessment program every five years. Most of them publish their compliance assessment report in line with the "Report on Standard 
and Codes" published by World Bank and IMF. FSB completes the country peer review and publishes its recommendations. A global code of conduct was issued in May 2017 to promote integrity and effective functioning of the wholesale foreign exchange market.

G-20 countries have established a MaP authority and inter-agency bodies to implement MaP regulations, strengthen system-wide monitoring and to manage financial stability risks. An oversight framework for hedge funds or their managers is also established, and there are requirements for oversight and registration of credit rating agencies.

To address data gaps and to assess international risks, FSB started a "G20 data gaps initiative", which was in its second phase in 2018. Under this initiative, G20 members enhance sharing granular data at national and international level. 500000 LEIs issued over 195 countries would help to collect information on parent entities, and aid FSB in regulatory activities especially with financial transaction reporting and correspondent banking.

BCBS is also working on measures to enhance timeliness and quality of information sharing among regulatory supervisors and promote cooperation between host and home countries of SIBs.

To address concerns about manipulation at the global level the robustness of interest rate benchmarks is being improved. Market participants are also working with authorities to identify risk-free benchmarks and increase their market use. Although migration away from the existing benchmark, LIBOR, in 2021 risks instability as contracts have to be re-priced, scope for market manipulation would reduce. Also inter-bank borrowing rates have become less important since many other money market instruments are now developed. Banks borrowing from each other will have less effect on their cost of funds.

\section{Key challenges and impact assessment}

BCBS evaluation of G-20 and other countries under FSB jurisdiction found 18 countries (containing $68 \%$ of the total market) to be largely compliant with risk-based capital rules while six European Union members (containing the remaining 32\% of the total market) were non-compliant. G-20 countries were fully compliant with the liquidity coverage ratio. Further, all 10 countries with G-SIFIs were compliant. 
Despite progress, some key regulations under Basel III standards due to be implemented during early 2017 were still delayed in most G-20 countries. These include capital requirements for equity investment, standardized approach for counter-party credit risk, the capital requirement for exposure to central counterparties, and margin requirement for noncentrally cleared derivatives. So country progress is not uniform. Delays prevent a level playing field and put extra pressure on compliant countries.

Reforms in financial market infrastructure have led to an increase in the number of CCPs for clearance of OTC derivatives, including those operating at cross-border levels. In post-trade services that include expanded portfolio reconciliation, there are better documentation practices and support for risk mitigation.

While reforms have increased rates of central clearing, liquidity and reduced spread in product markets, there are, however, views expressed that interaction of reforms may have reduced the depth of liquidity. Compliance cost has increased but has to be weighed against possible long-term benefits from increased financial stability. Banks have more capital but they also have more concentration and lower profitability.

BCBS analysis found strategic variation in bank's risk-weighted assets and recommended further revision of Basel III standards to reduce risk arbitrage. Shadow banking and liquidity management remains an issue. There are data and information sharing gaps.

There is pushback from markets (FSB 2018), which expect more volatility due to tough global standards and therefore want them to be made more risk sensitive. For example, they want cross border flows to be forced to have similar standards only if they are systemic.

QE has led to a rise in debt as a percentage of GDP from 145 in 2007 to 256 in 2017. At \$182 tr it is $60 \%$ higher than in 2007. In China alone it doubled to $300 \%$. For governments leverage increased 31 percentage points; non-financial corporates 29, and households 11 points. Corporate bonds increased 2.7 times to $\$ 11.7 \mathrm{tr}$, while credit quality fell. In China the CAGR was 39.9, other developing economies 14, AEs 7.8 - 10.5. Non-financial corporate debt ratio to GDP reached $73 \%$ in the US (Lund et al. 2018). Leveraged loans alternatives to bonds like mortgage-backed securities doubled since 2010 to more than $\$ 1$ tr, at the expense 
of credit standards. A majority of these loans had weak protection against default. A string of defaults could freeze lending to firms.

Strong BASEL III regulation targeting them led to arbitrage away from banks. Mutual Funds global assets under management increased from \$50 tr in 2004 to $\$ 79.3$ tr in 2016 and exchange-traded funds from $\$ 400 \mathrm{~b}$ in 2005 to $\$ 4.7$ tr in March 2018. Shadow banking has grown to $\$ 45.2$ tr. Growth was $7.6 \%$ in 2016 amounting to $13 \%$ of global financial assets (in 29 jurisdictions). It reached 2.5 times GDP in the US (FSB 2017). High asset prices make non-bank investors vulnerable to a rise in interest rates and possible crash in prices.

\subsection{Assessment of risks}

Even so, a distinction needs to be made between asset prices and excess leverage. If interest rates go up due to higher growth, asset prices may not crash. There is some diversification and discrimination among countries based on longer term fundamentals, and a long term movement away from the US towards diversified EMs.

The current leverage itself is different. While leverage of governments, firms and households has increased, financial sector leverage now comes from hedge funds not from banks. Equity funds lending arms are substituting for banks. Private equity is even buying banks and multiplying leverage. Even so, leverage in loan funds is $2: 1^{3}$, much less than the $30: 1$ banks had reached before the GFC. Private equity funds assets under management rose from nothing in 2006 to $\$ 200 \mathrm{bn}^{4}$. This is still less than $1 \%$ of banking assets but is a large share in smaller and more leveraged businesses. There are long-term investors who would lose but this would not be systemic unless growth collapses. But private equity does not have high quality assets or access to a lender of last resort facility as banks do.

However, annual gross cross border capital inflows, including foreign direct investment (FDI), debt securities, equity, and lending and other investment fell 53\% from a peak of 12.7 \$ tr in 2007 to 5.9 in 2017 (Lund et al. 2018). There are no large swaps as in 2008 when derivatives outstanding increased from $\$ 100$ tr in 2002 to $\$ 516$ tr in April 2007. The

\footnotetext{
${ }^{3}$ Equity Funds as the new banks https://www.ft.com/content/ec43db70-ba8e-11e8-94b2-17176fbf93f5

${ }^{4}$ Prequin research reported in the Economist September 8, 2018.
} 
unsecured inter-bank market has shrunk and there is reform to make manipulation in benchmark rates difficult.

Larger buffers and stronger capital rules, however, imply banks are retreating from traditional market maker roles of providing two-way quotes. There is therefore a question mark over liquidity supply. Can exits for trades become crowded especially as interest rates rise? Technology has enhanced market liquidity. For example, the adoption of MIFID II rules in Europe encouraged electronic trade. Volumes rose as the compliance burden fell. But algorithmic trade tends to be pro-cyclical.

Will this lead to more reliance on CBs? AE CBs are providing wider support, but should it continue? After the large expansion in balance sheets and extended period of low rates they now have little space for further stimulus. Moreover, after the experience of the GFC, lender of last resort power has been reduced for many CBs.

Cooperation among national authorities is required for regional and global financial stability because of large cross-border financial activity. It would create a level playing field and reduce regulatory arbitrage. Uneven pace of reform implementation leads to time-consuming bilateral recognition processes in the derivative regulatory framework. But the current political climate of populist nationalist rhetoric makes coordination difficult. Adherence to international standards, transparency in reporting, sharing resolution related information, maybe critical but is voluntary.

\section{The Emerging Market perspective}

From the EM perspective excessive focus of reforms on banks has been costly because their financial systems tend to be more bank focused. In addition, bank regulation together with QE encouraged arbitrage towards portfolio flows, increasing capital flow volatility for EMs. Since objectives (4) and (5) are aimed to address this volatility relatively slower progress in these items is a negative for EMs. In the post GFC period, and even before, EMs suffered from capital flow volatility, which was largely due to global risk-on risk-off, not the domestic cycle. Rey (2015) argues global risk off, when funds choose to return to the US, is largely due to US financial tightening. Periods of risk-off in 2011, 2013 and 2018 that followed the GFC have hurt EMs more than the GFC itself. And risk-on contributes to subsequent risk-off. 
The 19 largest EMs saw outflows of \$0.5tn in 2008/09 and \$1tn in 2014/15, recent risk-off periods. The IMF (2018) forecasts \$40-\$60bn outflows per annum during the period of QE exit; Lagarde sees this going up to \$100bn in 2019. Over risk on periods such as July 2009June 2014, when US interest rates were almost at the zero bound, EM inflows amounted to \$2tn. In 2017 they were \$160bn.

Although domestic macroeconomic vulnerabilities affected individual countries, the reasons for these surges were largely global. Low interest rates in AEs led to outflows in search of yield. Large liquidity made available through QE was multiplied through pro-cyclical balance sheets in financial institutions. In 2018, another risk-off year, US political actions such as sanctions against Iran led to an oil price rise, while its pro-cyclical fiscal stimulus strengthened the dollar.

EMs concerns remain peripheral. The $10^{\text {th }}$ anniversary, in 2018, of the Lehman crash stimulated a large amount of discussion, but hardly any from EMs point of view. 2011, 2013 and 2018 were actually larger shocks for EMs than 2008. Despite the G-20, not enough was done to moderate spillovers on EMs. This was short-sighted because EMs now account for a large and growing share of global GDP. AEs share, which was 54\% in 2004 fell to $41.31 \%$ in 2017. So an EM slowdown can now create negative spillovers for AEs, reducing world growth.

\subsection{Sources of negative spillovers to EMs}

\subsubsection{Bank dependence}

Compared to AEs, EMs remain much more bank dependent. Therefore decreasing cross border and trade finance, as regulations were tightened for banks, was a concern for them. EMs raised several issues during FSB's third annual EM forum (February 2017). Global regulatory reforms could conflict with the financing needs of these economies. Major implementation challenges of FSB regulatory reforms are related to domestic factors (narrow fixed-income markets, capacity constraints etc.) as well as cross-border spillovers. Bank lending grew slowly in some EMs whereas the non-bank sources of financing increased. As home jurisdictions of international banks implemented reforms (delays in bilateral recognition assessment of OTC derivatives, risk weighting of host countries' debt), adopted national policies to improve financial stability that went beyond internationally agreed 
standards, along with other macroeconomic developments such as slower growth, low commodity prices etc. the presence and activities of global banks reduced in some EMs.

\subsubsection{Cross-border banking flows}

Cross-border banking flows to EMs reduced and remained volatile in the post-GFC period. BIS consolidated banking data suggest that reduction in banking flows were mainly from US and UK whereas Japanese banks continued to increase their presence in EMs. Domestic and international banks were adversely affected due to emphasis on capital adequacy ratios in the Basel III framework. This reflected in the rising cost of funding, its availability, loan pricing and in a selection of countries. Rising interest rates in AEs could further reduce investors' appetite towards EM assets and add pressure on EM financial and non-financial corporates (Tiftik et al. 2017).

\subsubsection{Trade finance}

European and U.S. banks reduced their trade credit flows to EMs due to modest recovery since 2010. Some EM banks attempted to fill in the gap in financing needs, but tighter global funding conditions pose a risk for trade credit and these banks have lower capacity to fund cross-border trade. Since the Basel III framework does not fully identify risk profile of large corporations and banks and penalizes all off balance exposure, low-risk characteristics of trade finance would not be considered making it a less attractive portfolio for banks. Therefore, the higher capital requirement leads to a reduction in trade credit.

\subsubsection{Bank lending and debt capital markets}

The financial system in EMs is mostly bank dominated and financial markets are in a nascent stage of development. However, EM non-financial corporate bonds have grown substantially in the previous decade, reaching $\$ 4$ trillion in 2016 (Tiftik et al., 2017). Despite such a trend in the debt market, the domestic banking sector remains the primary source of funding in many EMs and accounts for more than half of non-financial corporate debt. Lack of external credit ratings of EMs corporates forces banks to increase their lending standards, in form of higher capital requirement, to lend to such firms. It negatively affects domestic and crossborder lending in EMs, and raises cost of capital.

\subsubsection{Corporate hedging}


EM non-financial corporate debt has increased from \$5trillion in 2005 to \$26 trillion in 2016 (Tiftik et al., 2017). Given such exposure in corporate firms in international markets, it becomes important for EM corporate to hedge interest rate risk, exchange rate risk, inflation risk etc.

The published Basel proposals sharply penalize trading activity that includes all financial instruments used for hedging purpose by SME and corporates. Proposed regulatory amendments create potential headwinds for corporates with foreign currency denominated debt through their negative impact on international funding available for hedging. During stressed periods, it might become difficult for EM corporates to pay foreign currency debt due to lack of foreign currency funding sources. Core sectors in EMs could be at larger risk due to lack of natural hedges and access to derivative markets. Corporate in the real estate and consumer sectors with local currency revenue and foreign expenses are more exposed to currency risk.

\subsubsection{Infrastructure investment}

Since infrastructure investment needs are higher compared to national saving especially in EMs, cross-border finance continues to an important source of funding for infrastructure investment. The post-crisis regulatory environment has made international banks reluctant to take a risk in this sector. Long-term infrastructure investment in EMs seems vulnerable to further de-risking by foreign banks. For regulatory purposes infrastructure project finance falls under Specialized Lending Exposure category of financing. According to the current Basel framework, these types of investment would not be assessed through the internal model and would require high collateral and guarantee from the government or credit agencies. This makes banks reluctant to fund such investment due to the risk of mispricing the cost of the investment.

Financial inclusion is another neglected area of particular importance to EMs. BCBS did issue guidance in 2016 on the application of Basel in the context of financial inclusion.

\subsubsection{Synchronization of macroprudential regulations}

Given the need to regulate cross-border capital to maintain financial stability in EMs, IMF (2011 and 2012) recognized that countries may have to 'synchronize' or co-ordinate macroprudential $(\mathrm{MaP})$ regulations at international as well as domestic levels, although there 
has been least progress in this area. MaP regulations mainly address systemic-wide financial risk within an economy. Countercyclical rules help to reduce market volatility, provide stability to the financial system, and obtain growth and investment objectives (Akdogan, 2012 and IMF, 2012). They mitigate balance sheet exposure from short-term debt flows, and reduce incentives to take risks, unlike capital controls that directly act on capital flows. But poorly designed and un-coordinated $\mathrm{MaP}$ regulations and capital flow measures such as aggressive capital controls might result in 'regulatory or capital war' and impose excess burden on a few countries, reducing global welfare (Jeanne, 2014 and Silva and Chui, 2017).

At the international level, EMs and AEs need to coordinate their policies to maintain global financial stability and mitigate negative spillovers which may constrain the supply of global capital. Coordination of $\mathrm{MaP}$ regulations with domestic monetary policy could control possible policy spillover. It is more important for EMs since they are exposed to cross-border flows and its mismanagement can have repercussion for their domestic financial stability.

International policy coordination has become more relevant in the post-crisis era. After GFC, EMEs faced excess capital flow volatility and its policymakers used several MaP tools to reduce the intensity and negative spillover of such inflows (Silva and Chui, 2017). Some MaP tools, such as countercyclical capital buffers, are relatively new and their possible spillovers are yet to be known. Given the size and outreach of several global banks, some form of international co-operation in MaP regulations could be helpful to not only restrain local credit booms but also affect the credit conditions in those economies where these banks have a larger presence. Global finance is highly mobile, adaptive and innovative which can generate negative externalities. Policy coordination would help to moderate excessive co-movements of asset prices globally and reduce the possibility of hasty capital controls or capital flow measures by any individual country (Cecchetti and Tucker, 2016). Exposure to risk across sectors, borders and institutions requires transparent exchange among authorities. It is beyond the ability of one supervisor to accurately aggregate information and to assess vulnerabilities. A common standard in MaP regulation would avoid regulatory arbitrage, fragmentation, and balkanization of the system. A key role of FSB is to promote such coordination among countries, identify vulnerabilities and address them in time.

On the domestic level of policy synchronization, monetary policy focusses on the intertemporal allocation of spending whereas MaP regulations restrain borrowing. Monetary 
policy mainly controls risk-free interest rates and MaP regulation focuses on risk premium or the spread between risk-free rate and lending rates (IMF, 2012). Achieving financial and price stability may not be possible with one instrument (via monetary policy) in case of capital account openness (IMF, 2012). For example, domestic currency appreciation due to capital inflows can lead to economic imbalances. Increase in policy rates alone may not be enough to dampen credit incentives. MaP policy alone is also inefficient to manage output and price stability because it highly restrains the financial sector. MaP regulations are more successful when it is complemented with the monetary policy (Bruno et al. 2015). A case study of five inflation targeting European countries (IMF 2012) shows policy interest rates can stay relatively low, reducing incentives for unhedged FX borrowing when complemented with MaP regulations. These also enhance monetary policy effectiveness and its transmission in small open economies.

Well designed and coordinated $\mathrm{MaP}$ regulations reduce the costs and tradeoffs. Claessens (2014) shows before the GFC MaP regulations were used 4 times more by EMs compared to AEs; after the GFC the gap reduced to 3.3. AEs use though increasing is still limited. This reduces coordination possibilities that can improve the effectiveness and reduce the costs of $\mathrm{MaP}$ regulations. In the section below we see the unilateral use of regulations in EMs faced with foreign portfolio flows.

\subsection{Regulation of foreign portfolio flows in EMs}

QE has led to an especially large rise in EM corporate debt and in fixed income flows to EMs.

Even so regulatory measures for cross border FPI flows to EMs are largely implemented in destination countries (EMs) with hardly anything for source countries (AEs).

Financial regulation of cross-border finance evolved over three generations of regulation. The first phase of regulation immediately after the Bretton Woods agreement was in the form of quantity-based controls such as restrictions on currency mismatches, minimum end-use restrictions, and minimum stay requirements. The second phase was price based such as unremunerated reserve requirement and minimum stay requirement in Chile, tax on inflows in Brazil and outflows in Malaysia (1998). Finally, in the third phase of financial regulation after the GFC, a few economies experimented with first and second-generation capital controls while others imposed regulations on foreign exchange derivatives to contain risk in 
currency and credit markets (Gallagher 2015). Some of the third-generation regulation EMs implemented were:

1. China: Outright ban or limit on entry of certain investments.

2. India: Directed limits on dollar-rupee trade, margin requirement on dollar-rupee trade increased to $100 \%$.

3. Brazil: Tax on portfolio investment ( $2 \%$ tax on bond and equities purchased by foreigners). Non-interest reserve requirement on short dollar position in FX spot market. These measures did not reduce the volume of capital inflows but switched foreign investment towards long-term investment.

4. South Korea: Withholding tax on non-resident holdings of treasury and monetary bonds; restrictions on bank FX derivatives. Liberalized capital outflows reduced net inflows and exchange rate pressures.

5. Peru: Tax on portfolio investment, position limits on FX short dollar trades and reserve requirement for all FX deposits. These did not, however, make a significant impact on the total inflows of capital or the composition of inflows.

6. Indonesia: One month holding period on central bank bills.

7. Thailand: Tax on nonresident purchase of public bonds.

Post GFC period also witnessed a more favourable view from the IMF on capital flow measures (CFMs) for EMs (IMF 2011, 2012). While capital account liberalization was to continue as the goal, it was recognized, the appropriate level of liberalization depends on institutional thresholds and country-specific circumstances. Nations should be cautious and sequenced when liberalizing the capital account. They should first liberalize FDI, then longer-term portfolio flows, and lastly short-term flows. Capital controls (now referred to as CFMs) may be used under certain circumstances.

Nations should, however, respond to inflow surges first with appropriate macroeconomic policies such as: allowing the exchange rate to appreciate; accumulating reserves; tightening fiscal policy or managing interest rates.

CFMs could be used if the exchange rate was not undervalued, reserves were at optimal levels or were too costly to accumulate further, the economy was overheating and there was little scope for fiscal tightening. CFMs can buy time for the first three, since inflow surges raise systemic risk. After a country has substantially liberalized its capital account, CFMs on 
capital outflows can be considered in crisis or near-crisis conditions, to provide breathing space while more fundamental policy adjustments are implemented. Even so, nations should give precedence to CFMs that do not discriminate on the basis of residency. They should be temporary and should be lifted when the conditions for their removal have been met.

Source countries (where capital flows originate) and nations deploying CFMs should be conscious of the multilateral aspects of their policies. Nations should strive for reciprocity when MaP policies are being deployed. The design of policies should "minimize the scope for regulatory arbitrage." The IMF recognizes that its advice on CFMs may be at odds with international trade and investment commitments of IMF members. De facto the onus remains on EMs, and there is little coordination. More market-based MaP regulations, such as those that reduce lowering of credit standards in source countries would allow EMs also to graduate to less distorting market-based regulations.

\subsection{Risks and EM's resilience: global liquidity tightening}

Post GFC, several EMs took advantage of easy external financial conditions to build buffers and correct economic imbalances but this also built financial vulnerabilities. Central banks in AEs normalized monetary policy in tandem with their gradual economic recovery, especially in the US leading to higher rollover risk, capital outflows and negative implications for productive investment for EMs. Depending on their domestic fundamentals, EMs experienced currency volatility and deterioration in debt sustainability with rising debt service due to increase in global interest rates.

IMF (2017) suggests that expected federal funds rate increase to 3.6 percent by early 2020 may lead to reducing portfolio flows in EMs, especially countries with weaker fundamentals, by $\$ 40$ billion a year in 2018-19. If policy normalization is accompanied by investors' risk aversion, capital portfolio flows could reduce by $\$ 60$ billion a year. EMs would be disproportionately affected due to in face of a rise in global interest rates (Sahay et. al 2014).

Shim and Shin (2018) show financial stress measured through CDS spread in AEs where international banks headquartered is a big driver of banking outflows from EMs. International banks decrease their exposure to EMs in face of financial instability in lender countries. Cross-border lending is more vulnerable to financial stress in lending countries compared to 
local lending by foreign banks. Diversification among financial lenders could be a way to reduce risk emanating through financial stress in lender countries.

However, except for a few, EMs are in a better position to withstand global volatility, with stronger macro-fundamentals, better reserve holdings and availability of cross-country swaps. After the East Asian crisis EMs increased the share of risk-sharing foreign equity investment compared to debt, which helped them survive the GFC. But the subsequent QE has led to a rise in corporate dollar debt in some EMs. They have also gained experience in macro and micro prudential regulations.

\subsection{Country experiences}

EMs are largely left to face global volatility on their own, but even the advice on how they should do this is not very clear. As a result, they tend to swing between extremes. But in the latest bout of global risk-off neither worked in vulnerable countries. Neither orthodox currency defense implemented by Argentina (with interest rates rising by $15 \%$ to $60 \%$ ) nor Turkey's heterodox polices (where despite Erdogan's resistance interest rates rose 24\%) were effective. Both their currencies depreciated by $40-50 \%$. Neither conservative pro-market nor idiosyncratic policies that ignore markets do well.

Context sensitive pragmatic counter-cyclical policies perform better. For example, China seems to be navigating trade shocks with counter-cyclical macroeconomic policies. After the post GFC credit boom there was contraction in attempts to contain shadow banking. But capital controls were increased after 2015-16 so that domestic interest rates can decrease even if US rates are rising. Cuts were implemented in CRR to increase liquidity.

In the post GFC period India saw large growth volatility, although its growth rate remained the highest in the world as growth slowed elsewhere. Its macroeconomic policies swung from too much stimulus to too much tightening. The post GFC G-20 coordinated macro stimulus was too large and aggravated already high commodity-led inflation. There was over-reaction after that as fiscal consolidation took place together with strictly implemented inflation targeting. There was some useful structural reform but in Larry Summers words 'stone-age monetary ideas' ruled in India. The micro and market fundamentalist view that only the supply-side determined output neglected the countercyclical actions that were feasible even with the flexible inflation targeting legally adopted. Systemic risk and possible financial 
instability from spillovers were also neglected. As a result industry and investment continued in a slowdown over 2011-2018, banks NPAs festered and grew, credit growth slowed and inadequacies in infrastructure financing manifested as concerns in non-bank financial companies also. Inflation did fall, but with major contribution from falling commodity prices.

The asset quality review undertaken by the RBI increased NPAs and provisioning, but the government was reluctant to recapitalize banks until the Indian Bankruptcy Code, 2017, was functional and there was some governance improvement. As a result bank credit fell steeply. As in AEs, there was a greater role for NBFCs and markets as banks retreated. This can be a healthy diversification that builds on local customer knowledge and fin tech to improve market stability. But for NBFCs in infrastructure, such as IL\&FS, that were financing long term assets with short-term debt, and funding more and more in short term money markets, under rising interest rates, the default was waiting to happen.

After the oil price crash of 2014, since the country was on an inflation targeting path, policy rates were not adequately adjusted downwards. Real interest rates were too high and investment and manufacturing collapsed, after a brief revival in 2014. The fall in oil prices turned India's net exports removing oil negative, implying a negative demand shock, which policy needed to alleviate. A rise in taxes on oil reduced a possible consumption boost from a fall in oil prices.

After 2011 Indian credit growth was the slowest among EMs; it actually turned negative for industry. Indian corporate dollar debt also did not rise as it did in most EMs in this period. Even borrowing limits available were not utilized, suggesting the credit slowdown was due to low demand. Industrial growth became negative in the April 2015 quarter after oil prices crashed, exports slowed, and the real interest rate reached a peak of 4 per cent.

A sharp fall in growth of gross fixed capital formation followed in the July 2016 quarter. As a result of the slowdown in industry, India was not able to take advantage of the boom in world exports.

As caps on debt inflows were lifted 2017 saw a surge of inflows, and real appreciation further hurt export growth. Debt inflows gained from appreciation, leading to more inflows. Intervention added $\$ 53$ bn to reserves in $2017-18$, but it was not enough to prevent 
appreciation over-fundamentals. Even so, the US treasury called it manipulation, and put India on their watch-list since one of their criteria is persistent one-sided FX intervention of at least $2 \%$ of GDP over 12 months. They recognized that India does not have a current account surplus but felt it does not need $\$ 400$ bn of reserves since it has capital controls. But excess inflows had come in, appreciating the rupee, precisely because controls had been relaxed. And reserves seemed inadequate in 2018 as oil prices touched $\$ 85$ and inflows were inadequate to finance the current account deficit. The rupee plunged despite interventions that only aimed to reduce excess rupee volatility.

The debt inflows did not help finance government borrowing either since the sterilizing swap of foreign for domestic securities only increased G-Sec yields.

Despite the perverse effects of high real interest rates, markets wanted a rise in policy repo rates in the October 2018 meeting to decrease domestic demand and increase inflows, suggesting the dominance of orthodox thinking opposing views on whether financial tightening or growth is necessary to review inflows. An interest rate defense of the rupee was attempted but did not work during the taper tantrum of 2013.

Majority of inflows are growth sensitive. Even debt inflows get capital gains from softening interest rates. If over depreciation indicates future appreciation and interest rates have peaked indicating future softening they are likely to return. This happened in India as oil prices crashed in November and the rupee appreciated ${ }^{5}$.

Impact of equity flows on Indian stock market indices has reduced since large domestic retail flows are coming in through mutual funds. Similar deepening of domestic debt markets is required before allowing more debt inflows. Retail fixed income flows are the most volatile and can create considerable interest rate volatility in thin markets that disrupts the domestic cycle.

India had a $0.5 \%$ policy rate rise in 2018 with debt inflows capped at $5 \%$ of the domestic market. Indonesia, where the share is $40 \%$ the rise was $1.75 \%$. Therefore the caps on debt flows need to be lifted more gradually, keeping in mind, not just the share of domestic debt

\footnotetext{
${ }^{5}$ Inflows of Rs1.9tn in liquid funds in October and November 2018, without any rise in policy rates in these months, largely reversed the Rs 2.1 tn outflow during September.
} 
market, but also international debt and impact on capital flows and intervention. This is an example of better domestic policy coordination.

Apart from direct intervention, there are many ways of financing an oil shock driven widening of the current account deficit and reducing rupee volatility in the short-term. For example, reducing oil companies' dollar demand by making dollar swaps available to them was the most effective measure in 2013. In the long-term, of course, the CAD has to be reduced through easier industrial conditions to stimulate exports, and substitution away from oil.

As strictly implemented inflation targeting led to a narrow focus there was poor coordination of monetary policy with capital flow management tools. The MPC acted as if the exchange rate was a float, although there was active intervention in the managed float. Coordinating MaP regulations, capital flow management and monetary policy could have given better results.

\section{Conclusion}

The G-20 financial reforms have seen many successes, and on the whole financial sector risks are lower than they were pre GFC. Although financial sector leverage is less, that of households, firms and governments is higher. EM corporate cross border leverage is regarded as a large potential risk as global interest rates rise towards normal. QE and the regulatory focus on banks have increased the volatility of portfolio flows to and from EMs, creating large fluctuations in interest and exchange rates, and therefore growth rates. EMs should not have to handle capital flow volatility alone.

EMs size has grown. They now account for more than $50 \%$ of global growth. Therefore preserving EM growth and reducing risks facing them aids global growth. AEs stand to lose as growth reduces in EMs. For example, global growth forecasts have been reduced after the volatility affecting EMs in 2018. Better coordinated prudential policies that are applied in source as well as destination countries can therefore benefit both. Better design can reduce tradeoffs, spillovers and costs.

At present policy advice and action are highly asymmetric. For example, EMs are advised to reduce fiscal spending to reduce reliance on and risks of foreign borrowing, while $\mathrm{AE}$ 
governments are advised to borrow more at the low interest rates prevailing. MaP regulations are not applied in AEs since they may increase the cost of financing, especially for the small borrower, but the effect of volatility in raising risk and rates throughout the world is ignored.

Since both conservative and heterodox policies have not been successful in dealing with capital flow volatility it would be helpful to build up a body of case studies for balanced context-based advice that co-ordinates monetary policy and MaP regulations with capital flow management, and creates better understanding of the nuances of and interactions among policies. The G-20 can help in this. Without better policies, there is a risk of democratic backlash in both EMs and AEs, against the open international financial system G-20 want to preserve.

Finally, there are many specific actions and institution building that can help EMs ride out global volatility. Calvo (2005) argues during risk-off episodes, spreads on debts rise even for EMs not undergoing a crisis. Indices such as the Morgan Stanley emerging market bond index (EMBI) show a sharp widening, implying the problem originates with creditors and their perceptions, not with the EMs. As EM firms' productivity or its perception becomes more volatile the returns to acquiring information rise. This increases price volatility, which causes further problems if firms are highly leveraged. Markets tend to underprovide information since it has a cost and benefits others (it creates an externality) - some EMs and firms are sound but the spread widens for all. Therefore institutions need to be created to provide credible information on EM firms. For example, a global emerging market fund (EMF) or a global information agency; or warranty or credit rating from international institutions. An EMF can help stabilize EM bond prices or spread index. The information provided by EMF support would be credible since it would be backed with money.

Liquidity facilities need to be further improved for EMs. More regional cooperation is improving the availability of bilateral CB swaps; an IMF backstop for these may decrease the moral hazard involved. Countercyclical infrastructure investment credit from international institutions can help smooth cycles. As international development banks are set up in EMs, competition among these banks may improve fund availability without compromising on credit standards. 


\section{References}

Akdogan, Idil Uz. 2018. "The Effects of Macroprudential Policies on Managing Capital Flows," Empirical Economics. pp. 1-21.

Bruno, Valentina, Ilhyock Shim, and Hyun Song Shin. 2017. "Comparative Assessment of Macroprudential Policies." Journal of Financial Stability 28 (February): 183-202. https://doi.org/10.1016/j.jfs.2016.04.001.

Calvo, G., 2005, 'Crises in Emerging Market Economies: A global perspective' http://www.nber.org/papers/w11305.pdf

Claessens, S. 2014. 'An Overview of Macroprudential Policy Tools,' IMF working paper no. WP/14/214. Available at https://www.imf.org/external/pubs/ft/wp/2014/wp14214.pdf

Cecchetti, Stephen G., and Paul Tucker. 2016. "Is There Macroprudential Policy Without International Cooperation?" CEPR Discussion Paper No. DP11042. Available at SSRN: https://ssrn.com/abstract=2717591.

Financial Stability Board. 2015. "Implementation and Effects of the G20 Financial Regulatory Reforms: 1st Annual Report." Report of the Financial Stability Board to G20 Leaders. Financial Stability board.

2016. "Implementation and Effects of the G20 Financial Regulatory Reforms: 2nd Annual Report.” Financial Stability board.

2017. "Implementation and Effects of the G20 Financial Regulatory Reforms: 3rd Annual Report." Financial Stability board.

Gallagher, Kevin. 2015. Ruling Capital: Emerging Markets and the Reregulation of CrossBorder Finance. Cornell Studies in Money. Ithaca, New York: Cornell University Press.

IMF. 2011. "Macroprudential Policy: An Organizing Framework.” IMF.

- 2012. "The Interaction of Monetary and Macroprudential Policies - Background Paper." IMF.

DC.

2017. "Is Growth at Risk?” Global Financial Stability Report, IMF. Washington,

2018. "Regulatory Reform 10 Years After The Global Financial Crisis: Looking Back, Looking Forward.” Global Financial Stability Report, IMF. Washington, DC.

Jeanne, Olivier, 2014. "Macroprudential Policies in a Global Perspective," CEPR Discussion Papers 9875, C.E.P.R. Discussion Papers.

Lund, S., A. Mehta, J. Manyika, and D. Goldshtein. 2018. 'A decade after the global financial crisis: What has (and hasn't) changed?' Executive Briefing McKinsey Global Institute. August.

Rey, Helene. 2015. 'Dilemma not Trilemma: The Global Financial Cycle and Monetary 
Policy Independence.' NBER Working Paper No. 21162. Available at https://www.nber.org/papers/w21162

Sahay, R., V. Arora, A. Arvanitis, H. Faruqee, P. N'Diaye, and T. M. Griffoli. 2014. "Emerging Market Volatility: Lessons from The Taper Tantrum." Staff Discussion Notes 14 (9): 1. https://doi.org/10.5089/9781498318204.006.

Shim, Ilhyock, and Kwanho Shin. 2018. "Financial Stress in Lender Countries and Capital Outflows from Emerging Market Economies.” BIS Working Papers 745 (September): 45.

Silva, Luiz Awazu Pereira da, and Michael Chui. 2017. "Avoiding 'Regulatory Wars' Using International Coordination of Macroprudential Policies." In Financial Volatility and Foreign Exchange Intervention: Challenges for Central Banks, 24.

Tiftik, E., J. Vazquez, J. Stallings, N. Bailey, and F. Nguyen. 2017. 'Basel Capital Reforms: Impact on Emerging Markets.' International Institute of Finance. Published on January 3, 2017. Available at https://www.iif.com/Publications/currentpage/87 